\title{
The Copper Thin Layer Deposition by Pulse Vacuum-Arc Sprayer
}

\author{
A. M. Zhukeshov*, A. T. Gabdullina, B. M. Ibraev, M. Mukhamedryskyzy, A. U. Amrenova, \\ E. Baltabai
}

Al-Farabi Kazakh National University, Almaty, Kazakhstan

Email: *zhukeshov@physics.kz

How to cite this paper: Zhukeshov, A.M., Gabdullina, A.T., Ibraev, B.M., Mukhamedryskyzy, M., Amrenova, A.U. and Baltabai E. (2020) The Copper Thin Layer Deposition by Pulse Vacuum-Arc Sprayer. Materials Sciences and Applications, 11, 177-183. https://doi.org/10.4236/msa.2020.113011

Received: January 11, 2020

Accepted: March 1, 2020

Published: March 4, 2020

Copyright $\odot 2020$ by author(s) and Scientific Research Publishing Inc. This work is licensed under the Creative Commons Attribution International License (CC BY 4.0).

http://creativecommons.org/licenses/by/4.0/

\begin{abstract}
In this work, the deposition process features of a copper coating on stainless steel substrate, using the pulse vacuum arc spraying method were researched. A continuous layer of copper was deposited on a stainless steel substrate, and a high degree of coating adhesion to the substrate was demonstrated. The thickness of coating using application time was calculated, and the surface unevenness was estimated. Inside the coating layer substrate material elements were observed, that could appear as a result of simultaneously plasma spraying on the surface of the substrate. The feature of this method was discovered, that surface plasma plays a significant role in the deposition process. Finally, it was shown that the device with a pulsed arc could effectively be used in industry, since it is possible to change the layer thickness in the range of hundreds of microns by varying the deposition time.
\end{abstract}

\section{Keywords}

Vacuum-Arc Plasma, Plasma Deposition, Copper Thin Layers, Microhardness

\section{Introduction}

The actual problems of materials science include the development of technologies for improving surface properties of various constructional materials and tools. One of the solutions to the tasks may be using plasma-spraying devices [1]. Plasma spraying is widely used in those branches of industry and technology, where it is necessary to protect the machine parts and tools from intensive wear, corrosion, erosion and to create the electrical layers [2]. Plasma vacuum deposition of functional coatings is obtained in vacuum equipment with a controlled environment and composition. Vacuum-arc accelerators (VAA) are 
widely used to change the structure of materials and for surface treatment of metals and alloys [3]. By applying a protective layer on the surface of materials, using VAA can improve their chemical composition and physical properties [4]. Therefore, the goal of this work is to develop the pulse vacuum arc sprayer and research technological advantages of this method to deposit copper layers on constructional steel.

\section{Experimental Devices and Samples}

In this paper, deposition experiments were carried out by experimental installation VAA-1, shown in Figure 1. The main elements of this accelerator are vacuum chamber, electrode system, DC power supply with energy store unit (capacitor battery) and pulsed ignition units. Electrode system of (VDU-1 installation) (Figure 1): the removable cathode with diameter $\mathrm{D}=50 \mathrm{~mm}$ is mounted on cathode holder with cylinder shape, connected to the cooling system (not shown in the figure). On cathode axis there is an orifice anode with $\mathrm{D}=90 \mathrm{~mm}$, which is connected to the power supply through a copper conductor placed inside ceramic insulation 2. The other conductor connected to the vacuum arc ignition electrode 4 . The ignition electrode is fixed at distance of $50 \mathrm{~mm}$ from the cathode surface. Plasma 5 formed at the anode outlet is deposited on substrate put on the holder6. Calorimeter 7 is included to research distribution of plasma flow 5 . The anode pulse current is measured by Rogowski belt 8 , which covers the anode wire in place close to the contact of vacuum chamber. The power supply source of VDU-1 consists of the capacitor battery with summarising the capacitance $600 \mu \mathrm{F}, 5000 \mathrm{~V}, \mathrm{DC}$ source for $500 / 1000 \mathrm{~V}, 10 \mathrm{~A}$ and a pulse generator with the passing frequency of $5-50 \mathrm{~Hz}$.

In the experiment, the samples of the test material are loaded into the working chamber at a residual air pressure of $1.33 \times 10^{-3} \mathrm{~Pa}\left(1 \times 10^{-5} \mathrm{mbar}\right)$. After the gas inflow, the sprayer mode sets and the pulse power generator switching on. In order to initiate the arc discharge the device design provides an ignition electrode made of stainless steel, situated in the shell of insulating material (ceramics),

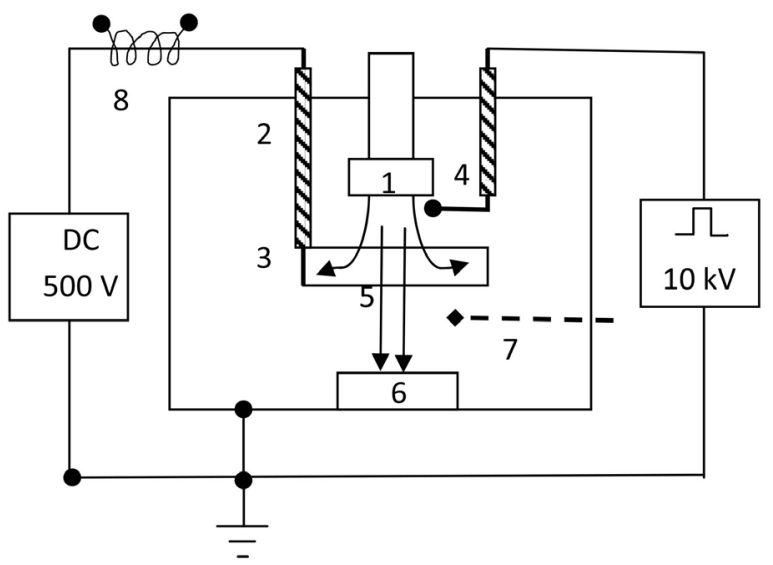

Figure 1. Installation scheme of VAA-1. 1-cathode, 2-isolator, 3-anode, 4-ignition electrode, 5-plasma flow, 6-substrate holder, 7, 8-diagnostic tools. 
and located near the cathode. Transmission of the ignition pulse with amplitude $\sim 10 \mathrm{kV}$ ensures the ignition of the arc discharge. The film on the cathode under the current action is evaporated and ionized in the area of ignition. Operation of the evaporator based on the erosive destruction of the surface layer of the cathode that provides stable combustion of a vacuum-arc discharge between the cathode and the anode. The sprayed material deposited on the surface of the stainless steel samples. The frequency of pulses is $5 \mathrm{~Hz}$, with the anode initial DC voltage of $500 \mathrm{~V}$, the average current about $1.5 \mathrm{~A}$, the processing time of $40 \mathrm{~min}$. The cathode is made from copper. To determine the efficiency of deposition process, 3 samples of stainless steel substrates were placed on a holder in one line and processed simultaneously.

The surface morphology of the copper coatings was studied using scanning electron microscope Quanta 2000. The chemical composition of the surface layer of material was determined by the X-ray secondary electron spectroscopy (RSA) on device Pegasus 2000. The microhardness measurements were carried out on metallographic microscope "METAVAL" at $\mathrm{P}=300 \mathrm{~N}$.

\section{Results and Discussion}

Table 1 shows composition of the substrate surface before (No. 7) and after deposition a copper layer (No. 1 and No. 3). RSA analysis was showed the efficiency of the deposition process, as so in chemical composition of the coating was found up to $71.38 \%$ copper (sample No. 1) and $92.56 \%$ (sample No. 3), respectively. The position of the samples on the holder explains the difference of the percentage content of copper in the samples. During the experiment sample, No. 3 was placed in the center, which increased the efficiency of the deposition. In addition, it was found the increase in carbon content from $2.09 \%$ to $16.76 \%$ and a decrease in iron and chromium $\sim 7$ and 12 times, respectively, which is evidence of internal rearrangements of the structure. The carbon apparently comes from the residual air or because of erosion of electrodes insulating of the accelerator.

Figures 2-4 show, the continuously copper layer deposited on substrate surface. There is inhomogeneous thin coating include same drops, that is usually of vacuum arc deposition process. The thickness of layer can be evaluated by spraying time, if we know the copper mass spraying coefficient for vacuum arc devices. This parameter has defined early by several experimentations [5] [6], and has difference value in range $70-150 \mu \mathrm{g} / \mathrm{Q}$.

Table 1. Composition of the surface of substrates after treatment by arc plasma.

\begin{tabular}{ccccc}
\hline Sample & C, mass $\%$ & Fe, mass $\%$ & Cr, mass $\%$ & Cu, mass \% \\
\hline No. 7 & 2.09 & 74.38 & 8.94 & - \\
No. 1 & 16.76 & 5.89 & 1.67 & 74.38 \\
No. 3 & - & 5.74 & 1.70 & 92.56 \\
\hline
\end{tabular}




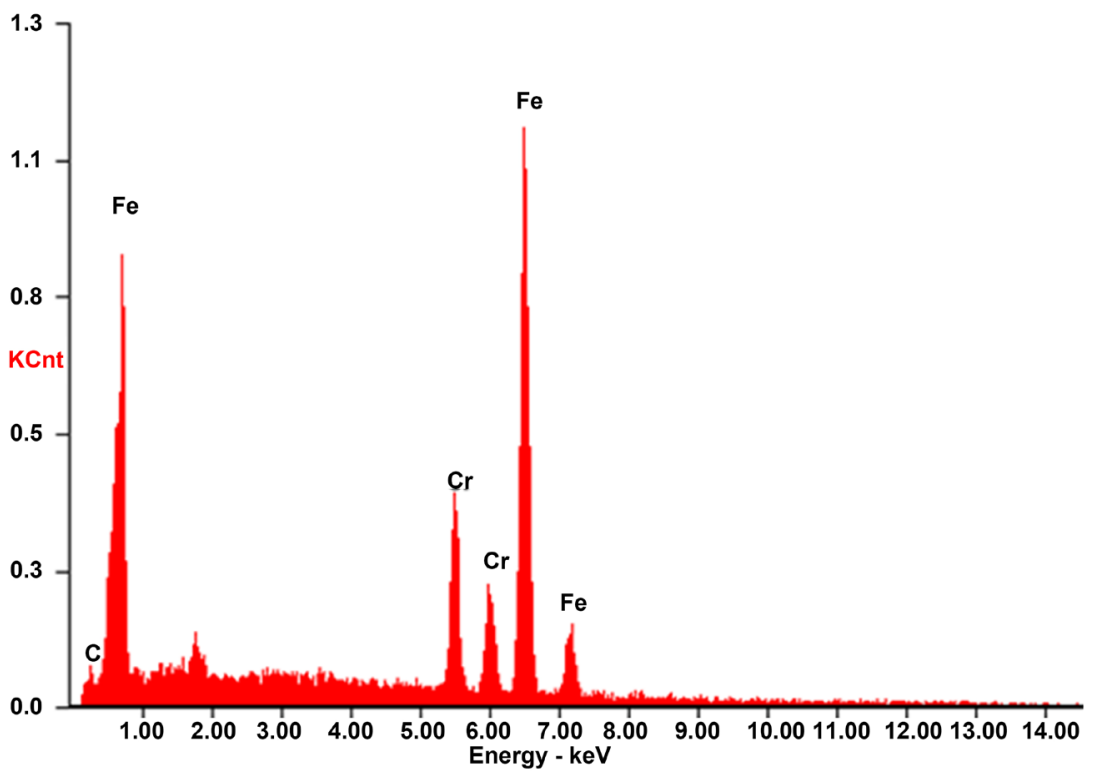

(a)

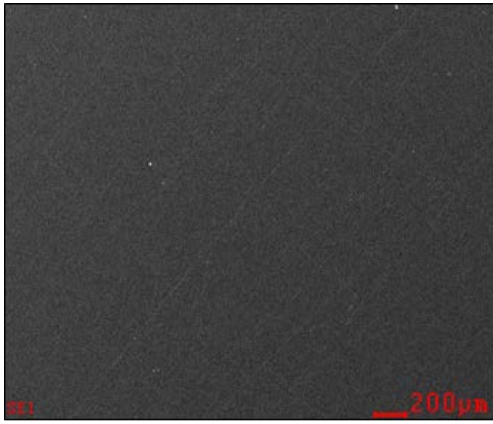

(b)

Figure 2. (a) The RSA spectrum of initial \#7 sample; (b) The surface of initial steel substrate.

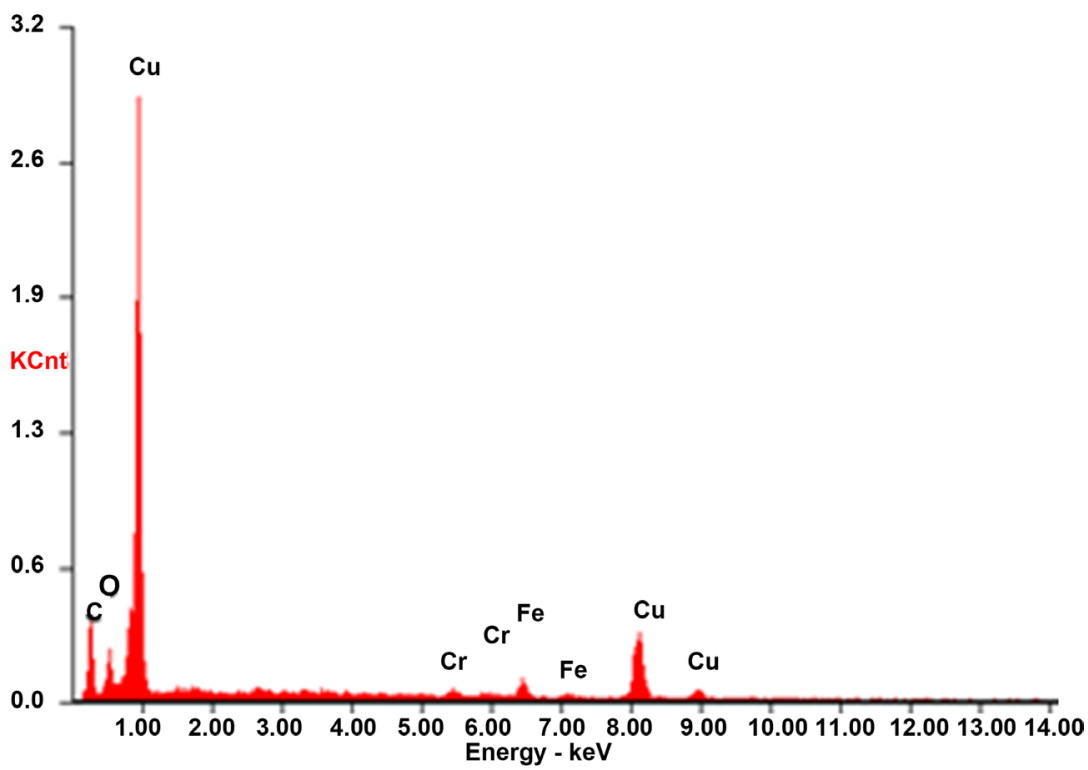

(a) 


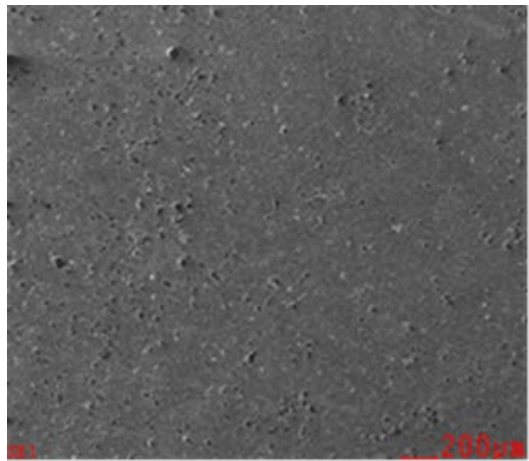

(b)

Figure 3. (a) The RSA spectrum \#1 sample; (b) The surface of \#2 substrate with copper coating.

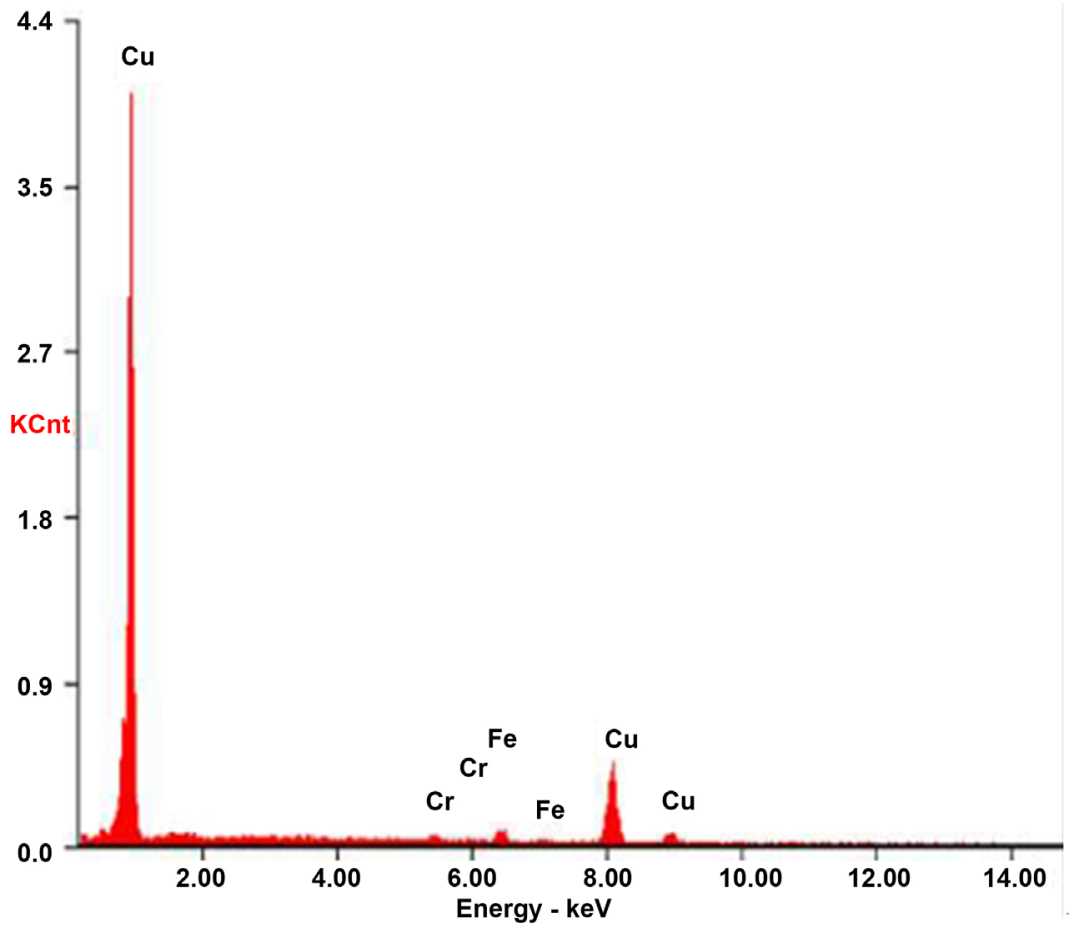

(a)

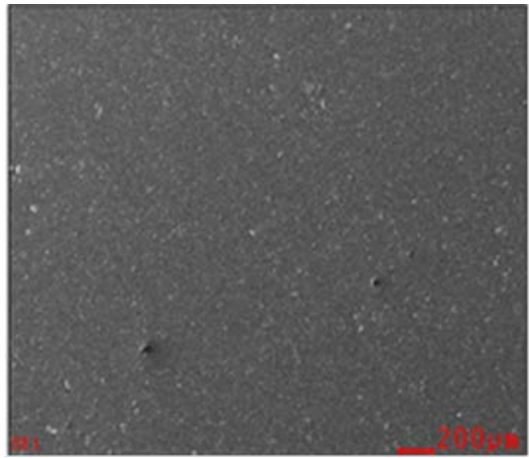

(b)

Figure 4. (a) The RSA spectrum \#3 sample; (b) The surface of \#3 substrate with copper coating. 
For the average mass transfer $100 \mu \mathrm{g} / \mathrm{Q}$ and current value of $1.5 \mathrm{~A}$, at frequency $5 \mathrm{~Hz}$ we obtain

$$
m_{c u}=100 \cdot 10^{-6} \cdot 1.5 \mathrm{~g} / \mathrm{s}=0.15 \mathrm{mg} / \mathrm{s} .
$$

Knowing the average time for one working cycle $t=40 \mathrm{~min}$, we can to calculate the copper layer mass for spraying:

$$
t \cdot m_{c u}=\rho \cdot S \cdot L,
$$

where $\rho$-density of copper; $S$-square of the deposited area, $L$-thickness of the sprayed layer. The density of copper is a tabular value of $8.96 \mathrm{~g} / \mathrm{cm}^{3}$. If deposition area is $100 \mathrm{~cm}^{2}$ (the diameter of plasma flow about $10 \mathrm{~cm}$ ), the thickness of the layer evaluated from formula (2) will be

$$
L=\frac{t \cdot m_{c u}}{\rho S} .
$$

The results of calculation presented on Table 2. So, the thin copper layer with thickness $400 \mu \mathrm{m}$ was deposited by VAA-1 device in time about $40 \mathrm{~min}$. This result demonstrated the good efficiency of researched method for coating obtaining.

The results of microhardness measurements were given in Table 3. As seen the copper layer was quite thin and did not affect substrate hardness. But changes in samples No. 1 and No. 3 could be traced, one of which was at the stream periphery. The thickness of the copper coating on sample No. 3 was maximum; therefore, when measuring microhardness, the imprint on this sample was the deepest, and this could be affected the value measured by the device. But the in homogeneity of hardness was about $255 / 261$ or $2 \%$ and we can say that the homogeneous coating was deposited.

\section{Conclusions}

This work shows the good efficiency of deposition of copper coating on stainless steel substrate using the pulsed vacuum arc spraying method. A continuous layer

Table 2. The copper layers thickness evaluated by (3).

\begin{tabular}{cc}
\hline Deposition time, min & $\mathrm{L}, \mu \mathrm{m}$ \\
\hline 20 & 192 \\
40 & 384 \\
60 & 576 \\
\hline
\end{tabular}

Table 3. The results of microhardness of the samples.

\begin{tabular}{cc}
\hline Sample & $\mathrm{M}, \mathrm{H}_{\mathrm{V}}$ \\
\hline No. 7 & 275.1 \\
No. 1 & 255.3 \\
No. 3 & 261.7 \\
\hline
\end{tabular}


of a copper was deposited on stainless steel substrate, which was a result of high degree adhesion of the coating to the substrate. The coating thickness altered using different depositing time was evaluated, and the non-uniformity of coating along the surface was calculated. Inside the coating, substrate material elements where observed, which could be attributed to simultaneously plasma spraying on the surface of the substrate. The feature of this method was found to be that surface plasma played a significant role in the deposition process.

The results can be used to develop industrial applications of the vacuum arc method. Currently, great prospects for development receive technology increases in the durability of structural materials and products from them. Proposed in this paper, time limit method for deposition of metallic materials using equipment of the type VAA-1 allows obtaining metallic coatings on substrates of structural steel with high efficiency and, requires low cost for production.

\section{Acknowledgements}

The work supported under research grants No. AP 05130108.

\section{Conflicts of Interest}

The authors declare no conflicts of interest regarding the publication of this paper.

\section{References}

[1] Lieberman, M.A. and Lichtenberg, A.G. (1994) Principles of Plasma Discharges and Materials Processing. John Wiley \& Sons Inc., Hoboken.

[2] Matrox, D.M. (2002) The History of Vacuum Coating Technology. Management Plus, Inc., Albuquerque, NM, USA.

[3] Aksenov, I.I. and Andreev, A.A. (1999) Vacuum-Arc Coating Technologies at NSC KIPT. Problems of Atomic Science and Technology, Series. Plasma Physics, 3, 242-246.

[4] Zhukeshov, A.M., Gabdullina, A.T. and Amrenova, A.U. (2016) Application of Vacuum Arc Deposition Surface Structural Materials. International Journal of Mathematics and Physics, 7, 102-105.

[5] Kimblin, C.W. (1973) Cathode Spot Erosion and Ionization Phenomenon in. the Cathode Spot Regions of Vacuum Arcs. Journal of Applied Physics, 44, 3074-3081. https://doi.org/10.1063/1.1662710

[6] Khoroshikh, V.M. (1986) Cathodic Erosion and the Cathode Mass Losses Instead-State Low-Pressurearc Discharge. PSE, 2, 184-199. 